\title{
Human ApoA-II Inhibits the Hydrolysis of HDL Triglyceride and the Decrease of HDL Size Induced by Hypertriglyceridemia and Cholesteryl Ester Transfer Protein in Transgenic Mice
}

\author{
Shaobin Zhong, * Ira J. Goldberg, ${ }^{\ddagger}$ Can Bruce, * Edward Rubin, ${ }^{\mathbf{5}}$ Jan L. Breslow," and Alan Tall* \\ $*$ Divisions of Molecular Medicine, ${ }^{\ddagger}$ Preventive Medicine and Nutrition, Department of Medicine, Columbia University, New York 10032; \\ ${ }^{\S}$ University of California, Lawrence Berkeley Laboratory, Berkeley, California 94720; and "The Rockefeller University, New York 10021
}

\begin{abstract}
The plasma cholesteryl ester transfer protein (CETP) mediates the exchange of HDL cholesteryl esters with triglycerides of other lipoproteins. Subsequent lipolysis of the triglyceride-enriched HDL by hepatic lipase leads to reductions of HDL size and apoA-I content. To investigate a possible modulation of the effects of CETP by apoA-II, human CETP transgenic mice were cross-bred with transgenic mice expressing human apoA-II and, in some cases, human apoAI and apoC-III (with human-like HDL and hypertriglyceridemia). CETP expression resulted in reductions of HDL and increases in VLDL cholesteryl ester in mice expressing human apoA-II, alone or in combination with apoA-I and apoC-III, indicating that apoA-II does not inhibit the cholesteryl ester transfer activity of CETP. However, CETP expression resulted in more prominent increases in HDL triglyceride in mice expressing both apoA-II and CETP, especially in CETP/apoA-II/apoAI-CIII transgenic mice. CETP expression caused dramatic reductions in HDL size and apoA-I content in apoAI-CIII transgenic mice, but not in apoA-II/AI-CIII transgenic mice. HDL prepared from mice of various genotypes showed inhibition of emulsionbased hepatic lipase activity in proportion to the apoA-II/ apoA-I ratio of HDL. The presence of human apoA-II also inhibited mouse plasma hepatic lipase activity on HDL triglyceride. Thus, apoA-II does not inhibit the lipid transfer activity of CETP in vivo. However, coexpression of apoAII with CETP results in HDL particles that are more triglyceride enriched and resistant to reductions in size and apoAI content, reflecting inhibition of hepatic lipase by apoA-II. The inhibition of HDL remodeling by apoA-II could explain the relatively constant levels of HDL containing both apoAI and apoA-II in human populations. (J. Clin. Invest. 1994. 94:2457-2467.) Key words: transgenic mice $\cdot$ cholesteryl ester transfer protein • apolipoprotein A-II • high density lipoproteins $\cdot$ hepatic lipase
\end{abstract}

\section{Introduction}

In most populations plasma high density lipoprotein levels are inversely correlated with the incidence of atherosclerotic cardio-

Address correspondence to Alan Tall, Department of Medicine, Columbia University, 630 W. 168 Street, New York, NY 10032.

Received for publication 6 April 1994 and in revised form 29 August 1994.

J. Clin. Invest.

(C) The American Society for Clinical Investigation, Inc.

0021-9738/94/12/2457/11 $\$ 2.00$

Volume 94, December 1994, 2457-2467 vascular disease $(1-3)$. The basis of this relationship remains poorly understood. In part this reflects the heterogeneity of HDL particles and the complexity of their metabolism. The two major apolipoproteins of HDL, apoA-I and apoA-II, are synthesized in the liver and apoA-I is also synthesized in the small intestine (4). However, much of the metabolism of HDL occurs within the intravascular compartment, where lipids and apolipoproteins are transferred between HDL and other lipoproteins. The plasma cholesteryl ester transfer protein (CETP)' mediates the heteroexchange of HDL cholesteryl ester and VLDL or chylomicron triglyceride (5). The subsequent action of hepatic lipase on triglyceride-enriched HDL is thought to produce a decrease in HDL particle size triggering catabolism of apoA-I (6). Human genetic deficiency of CETP results in marked increases in HDL cholesteryl ester and apoA-I levels, and increases in HDL size, indicating the importance of such remodeling processes in the in vivo catabolism of $\operatorname{HDL}(7,8)$.

The development of transgenic mice expressing human apolipoproteins and CETP has provided novel insights into lipoprotein structure and metabolism and atherogenesis (9). Human apoA-I transgenic mice have increased HDL cholesterol and apoA-I levels and humanlike speciation of HDL into discrete $\mathrm{HDL}_{2}$ and $\mathrm{HDL}_{3}$ subclasses (10). ApoA-I overexpression protects mice from the development of diet-induced atherosclerosis (11). ApoC-III transgenic mice display marked hypertriglyceridemia and reductions in HDL cholesterol (12). Mice normally lack significant plasma CETP activity. Expression of human CETP in transgenic mice leads to decreases in HDL cholesterol and apoA-I and decreased particle size $(13,14)$. At levels of CETP present in humans, reductions of HDL size and apoA-I levels are only appreciable in mice coexpressing human apoAI and/or human apoC-III transgenes, reflecting a favorable interaction of CETP with HDL containing human apoA-I (15) and an augmentation of lipid transfer and HDL remodeling by hypertriglyceridemia (16). Mice expressing very high levels of CETP develop early atherosclerotic lesions in the proximal aorta (17), confirming circumstantial evidence that CETP can have proatherogenic properties $(5,7)$.

Recently, apoA-II transgenic mice were developed $(18,19)$. Human apoA-II overexpression did not increase HDL cholesterol, but apoA-II altered HDL particle size distribution when coexpressed with human apoA-I. Interestingly, expression of apoA-II with apoA-I also diminished the antiatherogenic effects of apoA-I (19). Marked overexpression of mouse apoA-II in a transgenesis model resulted in increases in HDL cholesterol and

1. Abbreviations used in this paper: CE, cholesteryl ester; CETP, CE transfer protein; FC, free cholesterol; FPLC, fast protein liquid chromatography; rCETP, recombinant human CETP; TC, total cholesterol; TG, triglyceride; tg, transgenic. 
Table I. Plasma CETP and Lipid Concentrations in Transgenic Mice and Nontransgenic Littermates

\begin{tabular}{|c|c|c|c|c|c|c|c|c|}
\hline Apolipoprotein $\operatorname{tg}$ & CETP tg & & Human AI & Human AII & CETP & $\mathrm{TC}$ & TG & PL \\
\hline & & $n$ & $m g / d l$ & $m g / d l$ & $\mu g / m l$ & $m g / d l$ & $m g / d l$ & $m g / d l$ \\
\hline \multicolumn{9}{|c|}{ Mixed background } \\
\hline \multirow[t]{2}{*}{ None } & - & 9 & 0 & 0 & 0 & $59 \pm 2$ & $69 \pm 10$ & 166 \\
\hline & + & 7 & 0 & 0 & 2.3 & $38 \pm 5^{* \ddagger}$ & $74 \pm 7$ & 155 \\
\hline \multirow[t]{2}{*}{ AII } & - & 4 & 0 & 68 & 0 & $37 \pm 2^{\ddagger}$ & $92 \pm 7^{\ddagger}$ & 118 \\
\hline & + & 12 & 0 & 71 & 2.3 & $33 \pm 3^{\ddagger}$ & $97 \pm 8^{\ddagger}$ & 136 \\
\hline \multirow[t]{2}{*}{ AI-CIII } & - & 9 & 164 & 0 & 0 & $75 \pm 2$ & $555 \pm 28^{\ddagger}$ & 332 \\
\hline & + & 8 & 78 & 0 & 2.2 & $56 \pm 4 *$ & $602 \pm 78^{\ddagger}$ & 265 \\
\hline \multirow[t]{2}{*}{ AI-CIII/AII } & - & 8 & 75 & 64 & 0 & $54 \pm 2$ & $601 \pm 69^{\ddagger}$ & 240 \\
\hline & + & 8 & 83 & 63 & 2.4 & $49 \pm 2$ & $819 \pm 67^{* \neq}$ & 260 \\
\hline \multicolumn{9}{|l|}{ C57BL6 } \\
\hline \multirow[t]{2}{*}{ None } & - & 6 & ND & ND & 0 & $61 \pm 4$ & $47 \pm 11$ & ND \\
\hline & + & 3 & ND & ND & 3.7 & $45 \pm 7^{* \ddagger}$ & $47 \pm 12$ & ND \\
\hline \multirow[t]{2}{*}{ AII } & - & 7 & ND & ND & 0 & $32 \pm 3^{\ddagger}$ & $72 \pm 3$ & ND \\
\hline & + & 5 & ND & ND & 3.6 & $31 \pm 3^{\ddagger}$ & $74 \pm 5$ & ND \\
\hline \multirow[t]{2}{*}{ AI } & - & 8 & ND & ND & 0 & $90 \pm 6^{\ddagger}$ & $52 \pm 6$ & ND \\
\hline & + & 3 & ND & ND & 3.1 & $65 \pm 4 *$ & $43 \pm 5$ & ND \\
\hline \multirow[t]{2}{*}{ AI/AII } & - & 9 & ND & ND & 0 & $76 \pm 4^{\ddagger}$ & $63 \pm 6$ & ND \\
\hline & + & 4 & ND & ND & 4.0 & $50 \pm 3 *$ & $60 \pm 5$ & ND \\
\hline
\end{tabular}

Human apo-AI and AII were determined by ELISA and CETP was determined by RIA. The lipid levels were assayed by using standard enzymatic methods. ND, not determined. CETP Transgene -, means no CETP transgene is present; + , means the Mt-CETP transgene is present and has been induced with dietary $\mathrm{Zn} . n$, the number of mice in each group. ${ }^{*}$ Significantly different from the corresponding group with no CETP transgene $(P<0.05$ or better $)$. ${ }^{\ddagger}$ Significantly different from nontg mice.

size and promoted the development of proximal aortic fatty lesions even on a chow diet $(20,21)$. Although these studies suggest that apoA-II could have important effects on atherogenesis, they have provided limited information on the normal functions of apoA-II.

Studies of recombinant HDL particles containing apoA-I and apoA-II have suggested that apoA-II may inhibit the ability of CETP to produce smaller HDL particles $(22,23)$. Recently apoA-II was found to inhibit the ability of CETP to transfer CE from HDL to LDL (23). The limited accumulation of apoA-II in human genetic CETP deficiency could also indicate that HDL particles containing apoA-II are not optimal substrates for CETP (24). Biochemical studies have also suggested that apoA-II might inhibit hepatic lipase $(25,26)$, but the results have been conflicting depending on assay conditions (27). In the present studies the effects of apoA-II on HDL metabolism have been examined by crossing mice containing human apoA-II with human CETP transgenic mice. Since the effects of CETP are markedly enhanced by coexpression with human apoA-I and/ or human apoC-III, these studies included mice expressing these transgenes. The initial hypothesis was that apoA-II might inhibit the lipid transfer activity of CETP in vivo. Although this was not confirmed, the coexpression of apoA-II with CETP resulted in increased HDL triglyceride, and constrained the ability of CETP to reduce HDL particle size and protein content.

\section{Methods}

Transgenic mice. The transgenic mice used in the present investigation have been previously described $(10,15,16,18,28,29)$. Mice of the desired genotypes were created by cross-breeding the existing lines (Table I). The CETP transgenic mice were derived from a line of mice expressing a CETP minigene under the control of the mouse metallothionein promoter (mT-CETP transgenic mice [29]). To facilitate the development of mice expressing multiple transgenes, the apoA-I and apoC-III genes were present on the same transgene (16). The apoAICIII transgenic mice showed moderate overexpression of both human apoA-I and human apoC-III (16). Mice bearing multiple transgenes were obtained by crossing one heterozygote human apoA-II transgenic male with five heterozygous apoAI-CIII/CETP female mice. Thus, mice of eight different genotypes were produced (Table I, top). ApoAI-CIII and mT-CETP transgenic mice created at The Rockefeller University were in a mixed genetic background $(16 ; \mathrm{CBA} / \mathrm{J} \times \mathrm{C} 57 \mathrm{BL} 6 \mathrm{C})$, while those derived at University of California, Berkeley were in the C57BL6 background (apoA-I transgenic mice [line A116] and apoA-II transgenic mice [line A2F19]) $(10,18)$. To ensure that observed differences in phenotype were due to the transgene interactions, a limited number of experiments were also carried out in breeding mice towards the C57BL6 background. To this end the mT-CETP transgene was bred through more than five generations of C57 BL6 mice. One male C57BL6 mouse expressing both human apoA-I and apoA-II transgenes was crossed with five different mT-CETP females (towards C57BL6 background), producing mice of eight different genotypes (Table I, bottom).

The mice were screened using antibodies that specifically recognize human CETP, human apoA-I, and human apoA-II $(10,18,30)$. CETP was detected using ${ }^{125} \mathrm{I}$-TP2 (a monoclonal antibody to CETP) (30), in dot blots or in RIA, and confirmed by activity measurements (31). Human apoA-I and apoA-II were recognized by anti-human apoA-I and apoA-II antibodies raised in goats, using horseradish peroxidaseconjugated anti-goat IgG as secondary antibody. The genotype assignments were also confirmed by SDS-PAGE of isolated HDL and specific determinations of human apoA-I and apoA-II levels in plasma by immunoassay (Table I).

Mice of both sexes were housed in metabolic cages in a single room with a 12-h (7:00 a.m.-7:00 p.m.) light-dark cycle, and maintained on water and rodent chow (Purina Chow 5001; Ralston Purina Co., St. Louis, MO) ad lib. They were studied at 4-7 mo of age after supplemen- 
tation of the drinking water with $25 \mathrm{mM} \mathrm{ZnSO} 4$ for $7 \mathrm{~d}$ to induce the mT-CETP transgene (29). Mice not containing this transgene received the same treatment. Food was not removed from the cages. Blood was collected at about 10:00 a.m. through the tail vein into tubes containing $2 \mathrm{mM}$ NaEDTA, $500 \mu \mathrm{M}$ diethyl $p$-nitrophenylphosphate (E600; Sigma Chemical Co.), a lipase inhibitor. Plasma was stored at $4^{\circ} \mathrm{C}$ before analysis.

Lipoprotein analysis by fast protein liquid chromatography $(F P L C)$. Aliquots $(0.2 \mathrm{ml})$ of pooled plasma from all the mice in each genotype were applied to Superose 6 columns (two HR 10/30 columns connected in series; Pharmacia Inc., Piscataway, NJ), according to Jiao et al. (32). 40 fractions of $0.7 \mathrm{ml}$ were collected and analyzed for total cholesterol and triglyceride by enzymatic methods. The total cholesterol recoveries were $79-90 \%$ of the plasma values.

Analysis of HDL separated by preparative ultracentrifugation. Pooled plasma (all mice, $0.5-\mathrm{ml}$ aliquots) was centrifuged at 250,000 $g$ in an ultracentrifuge (Optima TL; Beckman Instruments, Inc., Fullerton, CA) using sequential densities of 1.055 and $1.21 \mathrm{~g} / \mathrm{ml}$ to isolate HDL. Plasma density was adjusted by addition of solid NaBr. HDL $(0.5 \mathrm{ml})$ was collected by tube slicing and dialyzed against Tris-EDTA buffer. Lipid measurements were carried out by enzymatic methods (33-36) using kits obtained from Wako Chemicals, Dallas, TX. The recovery for total cholesterol was $72-82 \%$. Protein content was determined by a modified Lowry assay (37). $25 \mu \mathrm{l}$ of HDL was electrophoresed on $4-16 \%$ SDS-polyacrylamide gels, stained with $0.05 \%$ Coomassie blue, then destained with $9 \%$ acetic acid $/ 20 \%$ methanol.

Immunoaffinity chromatography to isolate HDL particles containing apoA-I or apoA-I and apoA-II. Samples of pooled plasma (all mice, $0.8 \mathrm{ml}$ ) from AI-CIII/AII and AI-CIII/AII/CETP mice were treated with polyethylene glycol/glycine to remove VLDL and LDL, then applied to a human apoA-II immunoaffinity column, as described (18). The nonbound fraction (LpA-I) contained only apoA-I. The bound fraction (LpA-I/A-II) was released with $1 \mathrm{M}$ acetic acid. The apolipoprotein content of LpA-I and LpA-I/A-II was determined by immunoassay and SDS-PAGE, and the lipid content by enzymatic assay (33-36).

Lipoprotein size estimation by native polyacrylamide gel electrophoresis. Isolated HDL ( $25 \mu \mathrm{l})$ was subjected to electrophoresis on native 4-25\% polyacrylamide gradient gels (38). The gel was stained with $0.05 \%$ Coomassie blue then destained with $9 \%$ acetic acid $/ 20 \%$ methanol (39). Lipoprotein size was estimated by comparison with standard proteins (high MW calibration kit; Pharmacia Inc.).

Lipid transfer activity measurements. To compare HDL from mice of different genotypes as triglyceride acceptors, human VLDL containing radiolabeled triglyceride was prepared as follows: $250 \mathrm{nmol}$ ( 920 $\mu \mathrm{Ci})\left[{ }^{3} \mathrm{H}\right]$ triolein, $4.6 \mu \mathrm{mol}$ phosphotidylcholine, $22 \mathrm{nmol}$ butylated hydroxytoluene were dried under $\mathrm{N}_{2}$ and then sonicated with $2 \mathrm{ml}$ of a solution containing $50 \mathrm{ml}$ Tris, $0.01 \%$ EDTA, and $1 \mathrm{mM}$ DTT. The sonicated microemulsion was then incubated with human VLDL (12 mg protein) and pure recombinant human CETP (rCETP, $20 \mu \mathrm{g}$ ) for $20 \mathrm{~h}$ at $37^{\circ} \mathrm{C}$, followed by flotation of VLDL at $\mathrm{dl} .006 \mathrm{~g} / \mathrm{ml}$; this flotation removed the CETP. VLDL ( $5 \mu \mathrm{g} \mathrm{TG}, 20,000 \mathrm{cpm}$ ) was then incubated with mouse HDL ( $30 \mu \mathrm{g}$ protein) in the presence of $30 \mathrm{ng}$ rCETP for $0,0.5,1$, or $5 \mathrm{~h}$ at $37^{\circ} \mathrm{C}$ and $\mathrm{HDL}$ isolated by centrifugation at 1.055 $\mathrm{g} / \mathrm{ml}$, then counted.

Hepatic lipase activity determinations. Heparin (100 U/kg body wt; Elkins-Sinn, Inc., Cherry Hill, NJ) was injected into the leg vein of transgenic or nontransgenic mice under isoflurane anesthesia. Postheparin plasma was collected after $5 \mathrm{~min}$. Hepatic lipase activity in postheparin plasma $(10 \mu \mathrm{l})$ was measured using a gum arabic-stabilized emulsion containing $0.88 \mathrm{M} \mathrm{NaCl}$ in which lipoprotein lipase was inactive (40). To assess the effects of HDL isolated from mice of different genotypes on hepatic lipase activity, 0-50 $\mu \mathrm{g}$ of dialyzed mouse HDL

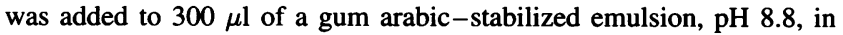
$1.25 \mathrm{M} \mathrm{NaCl}$ prepared as described by Baginsky and Brown (40). The assay was begun by addition of $10 \mu \mathrm{l}$ of mouse postheparin plasma (from nontransgenic [tg] mice) and allowed to continue for $1 \mathrm{~h}$ at $27^{\circ} \mathrm{C}$. The reaction was terminated by addition of $3.5 \mathrm{ml}$ of a solution of methanol, chloroform, heptane, and oleic acid (1,410:1,250:1,000:1/ vol:vol) and $1 \mathrm{ml}$ of $0.05 \mathrm{M}$ potassium borate buffer, $\mathrm{pH} 10$ (41). After centrifugation, $1 \mathrm{ml}$ of the aqueous phase was removed, $3.5 \mathrm{ml}$ of Hydrofluor (National Diagnostics, Manville, NJ) was added, and the amount of liberated free fatty acids was determined by liquid scintillation spectroscopy in a beta counter (LS 1000; Beckman Instruments). All assays were performed in triplicate and the experiment was performed twice using preparations of HDL from several groups of mice.

Plasma HDL cholesterol and triglyceride determinations after in vitro incubation with rCETP and diethyl p-nitrophenylphosphate (E600). Plasma was obtained from AI-CIII and AI-CIII/AII transgenic mice. An aliquot $(200 \mu \mathrm{l})$ of such pooled plasma was immediately stored in ice. At the same time, two other aliquots (200 $\mu \mathrm{l}$ each) were incubated with pure rCETP $(20 \mu \mathrm{g} / \mathrm{ml})$, with or without E600 $(500 \mu \mathrm{M})$ for $5 \mathrm{~h}$. Plasma HDL was subsequently isolated by ultracentrifugation between densities 1.055 and $1.21 \mathrm{~g} / \mathrm{ml}$, cholesterol and triglyceride were determined.

Statistical analysis. Total cholesterol (TC), cholesteryl ester (CE), free cholesterol (FC), triglyceride (TG), phospholipid (PL), and protein concentrations are presented as means \pm SEM. ANOVA was performed to determine the differences among groups. If an overall significance was found in ANOVA, the Fisher least significant difference test was then used to assess statistical significance. A Macintosh Stat View program was used to process the data and facilitate the calculations.

\section{Results}

To examine the interaction of apoA-II and CETP in vivo, mice expressing a human apoA-II transgene were crossed with mice containing human mTCETP and apoA-I/apoC-III transgenes, resulting in mice of eight different genotypes (Table I, top). In each case mice containing an active CETP transgene ( $\mathrm{Zn}$ induced) are compared with mice of the same genotype with no CETP transgene (shown as CETP transgene $-l+$ in Table I). Since these animals were genetically heterogeneous, a limited number of experiments were also carried out in mice bred towards the C57BL6 background; eight different genotypes were examined (Table I, bottom). These included four genotypes that were identical with those in mixed genetic background. Although apoC-III transgenic mice were not available in the C57BL6 background, an additional genotype comparison was possible, i.e., apoA-I plus apoA-II with and without CETP.

The plasma lipid, apolipoprotein, and CETP levels are shown in Table I. Within each set of animals plasma CETP was expressed at similar levels, i.e., 2.2 to $2.4 \mu \mathrm{g} / \mathrm{ml}$ in mice of mixed genetic background, and 3.1 to $4 \mu \mathrm{g} / \mathrm{ml}$ in C57BL6 mice (Table I). The reason for the slightly higher expression in C57BL6 is unknown. A number of expected effects of apolipoprotein transgene expression were noted $(10,15,16,18)$, i.e., apoA-I expression resulted in increased plasma cholesterol and apoA-I levels, and apoC-III expression was associated with marked hypertriglyceridemia $(10,16)$. Some effects were not anticipated. Thus, compared with nontransgenic mice, apoAII expression resulted in significantly lower levels of plasma cholesterol and significantly higher levels of plasma triglyceride, both in mixed genetic background and C57BL6 mice. The decrease in plasma cholesterol was found to be due to a reduced level of HDL cholesterol (see below). Plasma levels of human apoA-I were also found to be lower in the presence of human apoA-II. These findings are consistent with earlier studies showing that human apoA-II overexpression has different effects on HDL than mouse apoA-II overexpression $(10,18,21)$. These differences could reflect the dimeric structure of human apoAII vs monomeric mouse apoA-II or other species-specific differences. The increase in plasma triglyceride in mice expressing 
$\mathbf{A}$

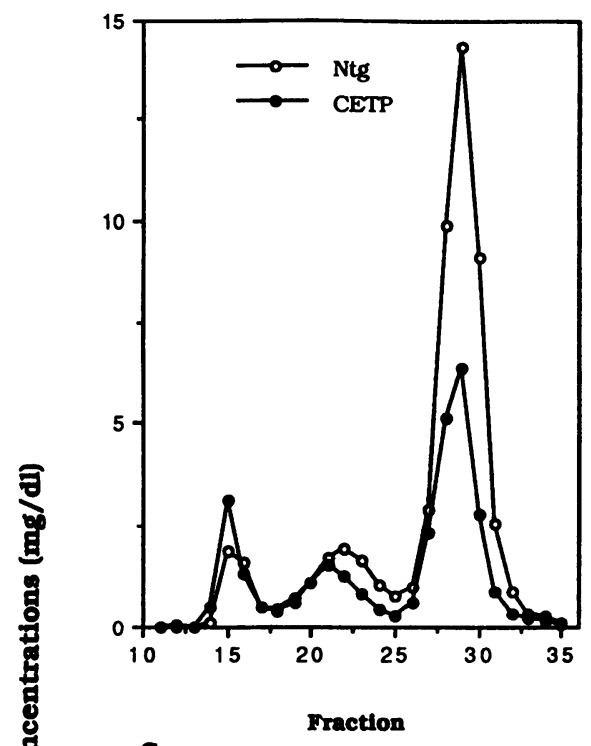

C

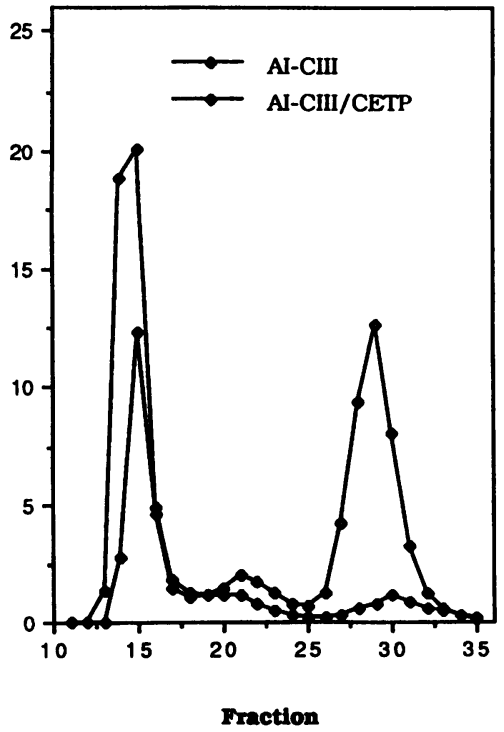

B

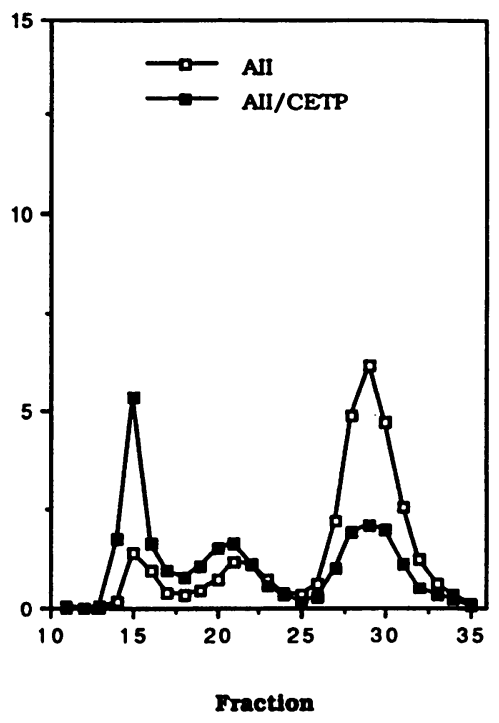

D

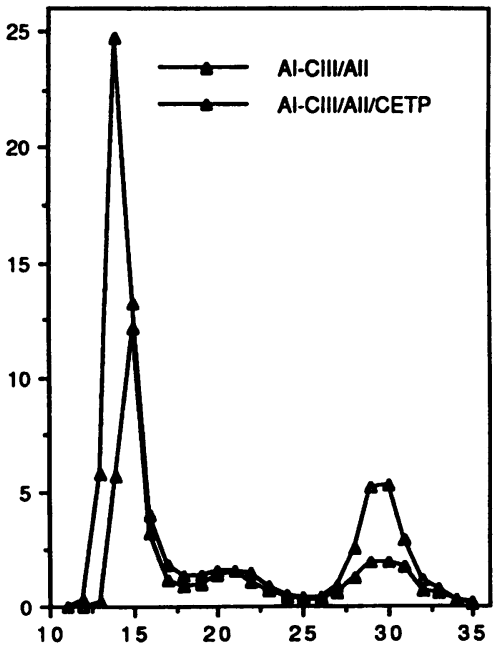

Fraction
Figure 1. Distribution of cholesterol in plasma lipoproteins separated by FPLC chromatography of pooled plasma. Aliquots of pooled plasma $(200 \mu \mathrm{l})$ from all the mice of each group were applied to two Superose 6 columns, connected in series, 40 fractions $(0.7 \mathrm{ml}$ each $)$ were collected and analyzed for TC using enzymatic kits (Wako Bioproducts). The data are expressed in milligrams cholesterol per deciliter plasma. human apoA-II is reminiscent of the more pronounced hypertriglyceridemia seen in mice expressing high levels of murine apoA-II (21), suggesting that this effect of apoA-II overexpression is not species specific.

The distribution of cholesterol amongst the plasma lipoproteins was determined by FPLC analysis of pooled plasma samples obtained on four separate sets of samples with similar results. The results for one set of samples are displayed in Fig. 1, showing differences in the profiles resulting from CETP expression. CETP expression caused a decrease in HDL cholesterol with only a slight increase in VLDL cholesterol (Fig. 1 $A)$. Even though HDL cholesterol levels were lower in the presence of human apoA-II, CETP expression still resulted in a marked decrease in HDL cholesterol (Fig. $1 B$ ). There was a reciprocal increase in VLDL cholesterol (Fig. $1 B$ ), explaining the lack of a significant reduction in plasma cholesterol levels as a result of CETP expression (Table I). CETP expression resulted in profound reduction of HDL cholesterol in apoAI-
CIII mice, and also resulted in an increase in VLDL cholesterol that was not as large as the reduction in HDL cholesterol (Fig. $1 C$ ). CETP expression produced a marked reduction of HDL cholesterol in AI-CIII/AII mice, with a matching increase in VLDL cholesterol (Fig. 1 D). Again the reciprocity of HDL and VLDL changes in the presence of apoA-II explains the lack of effect of CETP expression on total plasma cholesterol. Thus, apoA-II expression does not prevent the reduction in HDL cholesterol mediated by CETP. Furthermore, apoA-II expression leads to larger CETP-mediated increases in VLDL cholesterol, suggesting an impairment of the ability of CETP to produce net removal of cholesterol from plasma.

HDL was isolated by preparative ultracentrifugation of pooled plasma of mice of mixed genetic backgrounds (Table II). CETP expression resulted in reductions of HDL CE values in mice of each genotype, confirming the FPLC results. Although the starting levels of HDL CE were different for each genotype, the percent reduction due to CETP was relatively 
Table II. HDL Lipid and Protein Concentrations in Transgenic Mice (Mixed Genetic Background)

\begin{tabular}{lccccrr}
\hline Apolipoprotein tg & CETP tg & CE & FC & TG & PL & Protein \\
\hline \multirow{3}{*}{ None } & & & & & mg/dl plasma & \\
& - & $35.2 \pm 0.3$ & $4.7 \pm 0.9$ & $1.6 \pm 0.2$ & $71.6 \pm 7.9$ & $76.5 \pm 5.2$ \\
AII & + & $27.5 \pm 1.0$ & $3.5 \pm 0.6$ & $2.3 \pm 0.3$ & $57.1 \pm 1.1$ & $65.8 \pm 2.1$ \\
& - & $18.1 \pm 2.2$ & $2.5 \pm 0.2$ & $2.3 \pm 0.2$ & $34.7 \pm 3.5$ & $65.0 \pm 5.1$ \\
AI-CIII & + & $13.9 \pm 2.7$ & $1.7 \pm 0.2$ & $3.4 \pm 0.2$ & $27.4 \pm 2.9$ & $51.3 \pm 2.8$ \\
& - & $45.6 \pm 3.6$ & $6.3 \pm 0.6$ & $3.9 \pm 0.4$ & $98.2 \pm 8.9$ & $115.0 \pm 9.8$ \\
AI-CIII/AII & + & $9.1 \pm 1.4$ & $0.9 \pm 0.2$ & $3.9 \pm 0.3$ & $16.4 \pm 1.7$ & $37.5 \pm 4.9$ \\
& - & $23.3 \pm 2.2$ & $3.1 \pm 0.3$ & $3.2 \pm 0.5$ & $52.0 \pm 7.1$ & $71.5 \pm 3.7$ \\
& + & $9.0 \pm 1.3$ & $1.2 \pm 0.2$ & $5.6 \pm 0.2$ & $27.0 \pm 1.5$ & $69.5 \pm 11.3$ \\
\end{tabular}

Pooled plasma $(0.5 \mathrm{ml})$ was centrifuged at $150,000 \mathrm{~g}$ at sequential densities 1.055 and $1.21 \mathrm{~g} / \mathrm{ml} \mathrm{HDL}(0.5 \mathrm{ml})$ was collected by tube slicing (see text). TC, FC, TG, and PL were determined using enzymatic kits (Wako Bioproducts). CE was calculated as the difference between TC and FC. Protein content was determined by a modified Lowry assay. The values and standard errors were obtained by averaging six measurements from three centrifugations of pooled samples.

unaffected by the presence of human apoA-II, i.e., $22 \%$ for nontg versus CETP compared to $23 \%$ for A-II vs A-II/CETP; and $80 \%$ for AI-CIII vs AI-CIII/CETP compared to $61 \%$ for AI-CIII/AII vs AI-CIII/AII/CETP.

CETP expression led to slight increases in HDL triglyceride levels, but the increase in HDL triglyceride was more pronounced in mice expressing both apoA-II and CETP. This increase in HDL triglyceride was most pronounced in hypertriglyceridemic mice, i.e., in AI-CIII/AII vs AI-CIII/AII/CETP mice. The interaction of apoA-II and CETP to produce increases in HDL triglyceride was confirmed in mice bred towards the C57BL6 background, where CETP produced a larger increase in HDL triglyceride in AII vs AII/CETP, and AI/AII vs AI/ AII/CETP mice than in mice of the other genotypes (Table III). CETP expression also produced significant decreases in HDL phospholipid levels (Table II). However, the absolute and percent reduction of HDL phospholipid was much smaller in the presence of the human apoA-II transgene (e.g., 83\% decrease in AI-CIII/CETP mice vs 44\% AI-CIII/A-II/CETP mice). Analysis of individual HDL phospholipids showed no major change in the percentage of phosphatidylcholine, sphingomyelin, or

Table III. HDL Lipid Concentrations in Transgenic Mice (Bred towards C57BL/6 Background)

\begin{tabular}{lcccc}
\hline $\begin{array}{c}\text { Apolipoprotein } \\
\text { tg }\end{array}$ & $\begin{array}{c}\text { CETP } \\
\text { tg }\end{array}$ & CE & FC & TG \\
\hline \multirow{4}{*}{ Non } & & & mg/dl plasma & \\
& - & $34.5 \pm 0.4$ & $3.6 \pm 0.1$ & $1.7 \pm 0.1$ \\
AII & + & $28.9 \pm 0.3$ & $4.1 \pm 0.6$ & $1.9 \pm 0.1$ \\
& - & $23.0 \pm 0.5$ & $2.4 \pm 0.4$ & $1.3 \pm 0.3$ \\
AI & + & $14.0 \pm 0.9$ & $2.0 \pm 0.2$ & $2.2 \pm 0.1$ \\
& - & $55.5 \pm 4.6$ & $8.6 \pm 1.2$ & $1.9 \pm 0.2$ \\
AI/AII & + & $42.6 \pm 4.2$ & $9.2 \pm 0.9$ & $1.9 \pm 0.1$ \\
& - & $46.2 \pm 2.0$ & $5.8 \pm 0.5$ & $1.3 \pm 0.3$ \\
& + & $18.7 \pm 2.2$ & $4.4 \pm 0.6$ & $2.4 \pm 0.1$
\end{tabular}

HDL was isolated and analyzed as described in Table II. The values were the average of four measurements from two centrifugations of pooled samples. phosphatidylethanolamine as a result of A-II or CETP expression, as determined by thin layer chromatography (not shown).

To ensure that the changes in HDL triglyceride in hypertriglyceridemic mice did not reflect contamination of the HDL fraction by VLDL, triglyceride was measured in the HDL region of FPLCseparated pooled plasma of mixed genetic background mice (Fig. 2). This confirmed a marked increase in HDL triglyceride due to CETP expression in AI-CIII/AII mice but not in AI-CIII mice. Analysis of the VLDL-LDL regions of the FPLC profiles indicated that increases in plasma triglyceride (Table I) reflected alterations in VLDL triglyceride levels (not shown).

Total protein was determined on ultracentrifugally isolated HDL (Table II) and individual apolipoproteins were analyzed by SDS-PAGE of HDL (Fig. 3). CETP expression produced a marked decrease in total HDL protein in apoAI-CIII transgenic

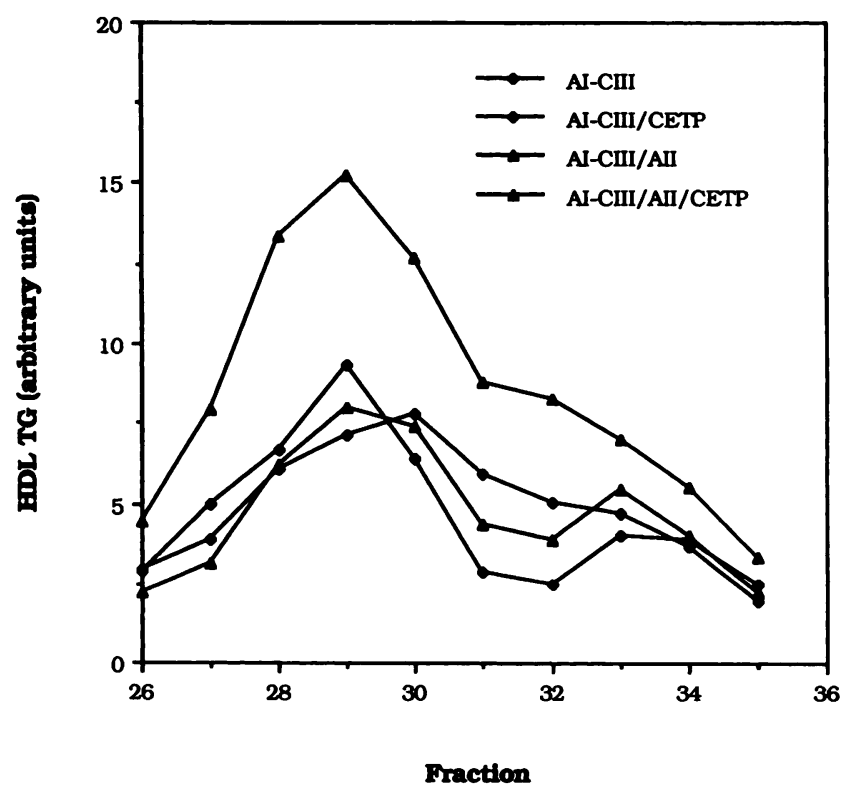

Figure 2. Triglyceride distributions in FPLC-separated plasma in the HDL region. The FPLC and TG measurements were performed as described in Methods. Triglyceride concentrations are expressed in arbitrary units. 


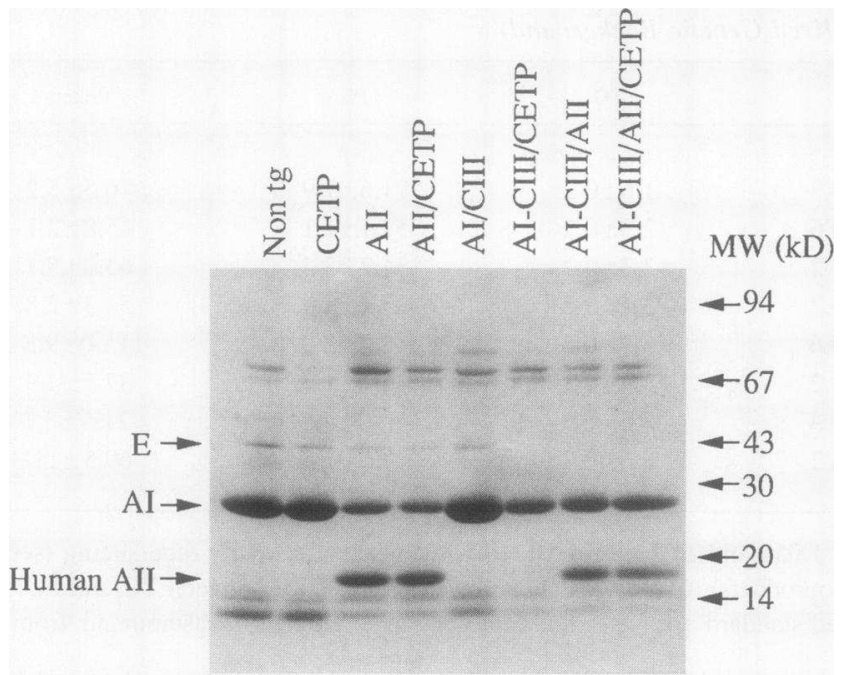

Figure 3. SDS-PAGE analysis of HDL apolipoproteins. Pooled plasma $(0.5 \mathrm{ml})$ was centrifuged at $250,000 \mathrm{~g}$ in an ultracentrifuge (Optima TL; Beckman Instruments) and HDL isolated between densities 1.055 and $1.210 \mathrm{~g} / \mathrm{ml}$. HDL (top $0.5 \mathrm{ml}$ of $1.21 \mathrm{~g} / \mathrm{ml} \mathrm{spin)} \mathrm{was} \mathrm{collected} \mathrm{by}$ tube slicing. HDL ( $25 \mu \mathrm{l})$ was electrophoresed on 4-16\% SDS-polyacrymide gels stained with $0.05 \%$ Coomassie blue, then destained with 9\% acetic acid and $20 \%$ methanol.

mice (Table II), due to a reduction in apoA-I (Table I; Fig. 3 ). There were also reductions in minor HDL proteins, i.e., apoE and apoCs (Fig. 3). In contrast, there was little change in total HDL protein (Table II), or in individual HDL proteins (Fig. 3) as a result of CETP expression in apoAI-apoCIII/ apoA-II transgenic mice. The band intensities determined by laser densitometry of the gel shown in Fig. 3 were: human + mouse apoA-I: nontg, 2,111 arbitrary units; CETP tg, 1815; AII tg, 738; AII/CETP tg, 641; AI-CIII tg, 2635; AI-CIII/CETP tg, 1023; AI-CIII/AII tg, 1210; AI-CIII/AII/CETP tg, 1131; human apo-AII: AII tg, 925; AII/CETP tg, 857; AI-CIII/AII tg, 700; AI-CIII/AII/CETP tg, 686. Similar SDS-PAGE results were obtained on three sets of pooled samples. These results are consistent with plasma levels of human apoA-I and human apoA-II in these animals (Table I).

The analysis of HDL lipids in mice of different genotypes indicated a significant enrichment of HDL triglycerides due to coexpression of human apoA-II and CETP. To see if the effects of apoA-II on HDL triglyceride were restricted to particles containing human apoA-II (i.e., LpA-I/A-II), HDL particles were isolated from plasma using a human apoA-II immunoaffinity column. There was a decrease in $\mathrm{CE}$ and a marked increase in the triglyceride content of the LpA-I/A-II fraction as a result of CETP expression, resulting in a change of the CE/TG ratio from 10.6 to 3.0 (Table IV). In contrast the LpA-I fraction showed no change of triglyceride content as a result of CETP expression. SDS-PAGE confirmed that the LpA-I/A-II fraction contained both apoA-I and apoA-II and showed no change in total or individual apolipoprotein content in this fraction as a result of CETP expression; by contrast, the flow-through fraction contained only apoA-I (not shown). These results indicate that the ability of apoA-II to increase HDL triglyceride in the presence of CETP is mediated by an effect of apoA-II exerted within particles containing apoA-II.

The size of HDL particles was determined by native gradient
Table IV. Lipid Compositions of Immunoaffinity Isolated HDL Fractions

\begin{tabular}{|c|c|c|c|c|c|c|}
\hline & $\mathrm{CE}$ & FC & TG & $\mathrm{CE} / \mathrm{TG}$ & PL & $\mathrm{CE} / \mathrm{PL}$ \\
\hline & \multicolumn{6}{|c|}{ mg/dl plasma } \\
\hline \multirow[t]{2}{*}{ Group } & \multicolumn{6}{|c|}{ AI } \\
\hline & \multicolumn{6}{|c|}{ Fraction } \\
\hline -CETP & 7.1 & 1.0 & 0.6 & 12.2 & 10.7 & 0.7 \\
\hline \multirow[t]{3}{*}{ +CETP } & 5.3 & 0.6 & 0.5 & 11.0 & 9.9 & 0.6 \\
\hline & \multicolumn{6}{|c|}{ AI/AIII } \\
\hline & \multicolumn{6}{|c|}{ Fraction } \\
\hline -CETP & 15.0 & 0.7 & 1.4 & 10.6 & 22.5 & 0.7 \\
\hline +CETP & 7.8 & 0.7 & 2.6 & 3.0 & 17.9 & 0.4 \\
\hline
\end{tabular}

Pooled plasma samples $(0.8 \mathrm{ml})$ from transgenic mice expressing apo AI-CIII/AII \pm CETP were applied to an apo-AII immunoaffinity column, after removal of VLDL and LDL by polyethylene glycol precpitation. The A-I fraction was the column flow-through (not bound). The bound fraction (AI/AII) was eluted with $1 \mathrm{M}$ acetic acid. CE, FC, TG, and PL concentrations in both fractions were determined by enzymatic methods in triplicate. The values are expressed as milligrams per deciliter plasma.

gel electrophoresis of centrifugally isolated HDL stained for protein with Coomassie blue (Fig. 4), then subjected to gel scanning by laser densitometry. Nontransgenic mice have a single monodisperse HDL fraction (peak diameter $9.8 \mathrm{~nm}$, intensity 4,150 arbitrary units), with only minor size changes resulting from CETP expression (peak $9.6 \mathrm{~nm}$, intensity 3,892 units). Apo A-II transgenic mice contain two HDL fractions, including a smaller population of particles enriched in human apoA-II (18) (peaks 9.4 and $8.3 \mathrm{~nm}$, intensities 2,093, 367, respectively); neither was greatly influenced by CETP expression (peaks 9.4 and $8.3 \mathrm{~nm}$, intensities 1,579, 254). By contrast apo AI-CIII transgenic mice displayed speciation of HDL into

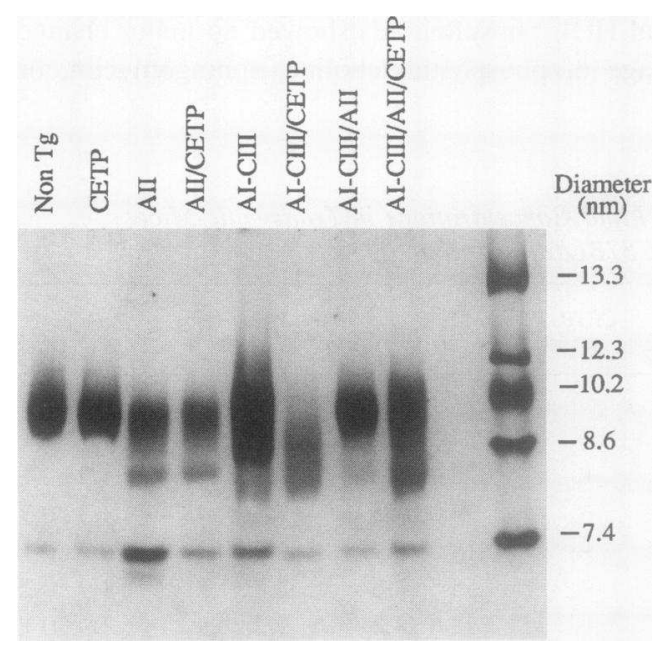

Figure 4. Native polyacrylamide gradient gel electrophoresis of HDL. Centrifugally isolated HDL ( $25 \mu \mathrm{l}$, see Fig. 3 legend) was subjected to electrophoresis on native 4-25\% polyacrylamide gradient gel, stained with $0.05 \%$ Coomassie blue, then destained with $9 \%$ acetic acid $/ 20 \%$ methanol. The migration position of standard proteins (high MW calibration kit; Pharmacia Inc.) is shown. 


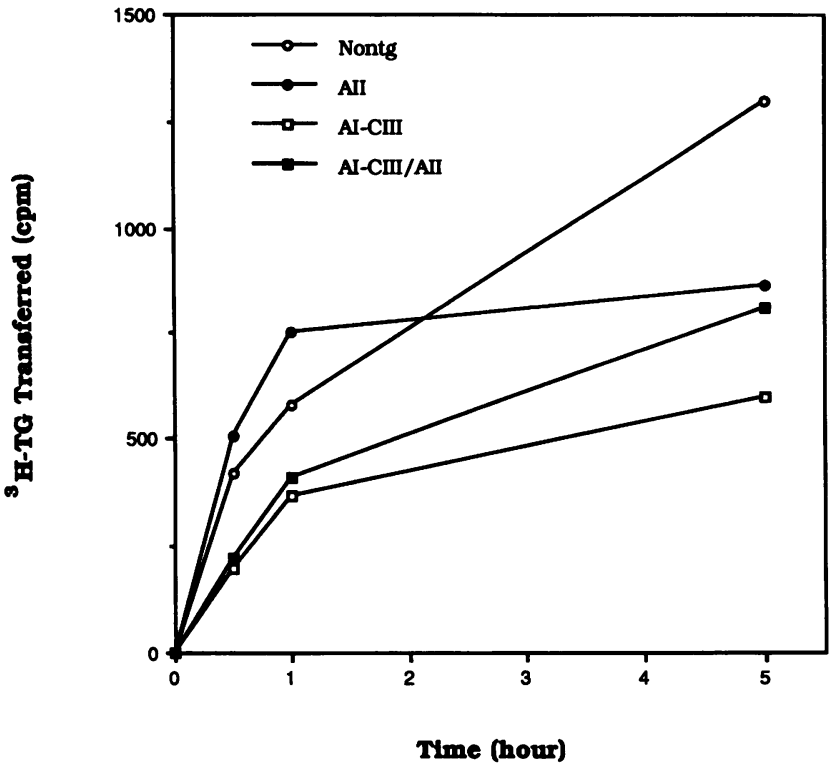

Figure 5. Triglyceride transferred from VLDL to HDL of different transgenic mice by purified CETP. VLDL containing radiolabeled triglycerides was prepared as described in Methods. VLDL (containing 5 $\mu \mathrm{g}$ TG, $20,000 \mathrm{cpm}$ of $\left[{ }^{3} \mathrm{H}\right]$ triolein) was incubated with mouse HDL ( $30 \mu \mathrm{g}$ protein) in the presence of $30 \mathrm{ng}$ purified human rCETP for the times shown at $37^{\circ} \mathrm{C}$ and $\mathrm{HDL}$ subsequently isolated by centrifugation at $1.055 \mathrm{~g} / \mathrm{ml}$, then counted.

larger and smaller populations (peaks 10.5 and $9.0 \mathrm{~nm}$, intensities $6,170,5,999$ ) and there was a marked decrease in size and protein staining as a result of CETP expression, producing much smaller particles (peak $8.5 \mathrm{~nm}$, intensity 1,587). When apo A-II was coexpressed with the AI-CIII transgene, most of the HDL was in a single major population (peak $9.5 \mathrm{~nm}$, intensity 4,957 ) with a minor small population (peak $8.1 \mathrm{~nm}$, intensity 171). CETP expression on this background produced a relatively minor increase in the smaller peak with little change in overall protein staining (peaks 9.5, $8.1 \mathrm{~nm}$, intensities 4,021, 930). Thus, CETP expression produces a profound reduction in HDL size in AI-CIII tg mice, but only minor size changes in $\mathrm{AI}-\mathrm{CIII} / \mathrm{AII}$ tg mice.

To investigate the mechanism of HDL triglyceride enrichment by coexpression of apoA-II and CETP, we first considered the possibility that apoA-II might stimulate the triglyceride transfer activity of CETP. Small amounts of human VLDL containing radiolabeled triolein were incubated with isolated HDL from mice expressing different human apolipoproteins in the presence of pure recombinant human CETP (Fig. 5). The major difference was a lower initial rate of TG transfer from VLDL to $\mathrm{HDL}$ of $\mathrm{AI}-\mathrm{CIII}$ or AI-CIII/AII transgenic mice, compared with HDL of nontransgenic and apoA-II transgenic mice. The presence of human apoA-II resulted in slight increases in the initial TG transfer rate compared to equivalent HDL without apoA-II. However, the latter differences were considered within the experimental error. Thus, there was no overall correlation of TG transfer rates with differences in HDL TG resulting from CETP expression in vivo, where the largest effect was seen in AI-CIII/A-II mice (Table II).

We next considered the possibility that the enrichment of HDL triglyceride and the preservation of HDL size and protein content due to coexpression of apoA-II and CETP genes could

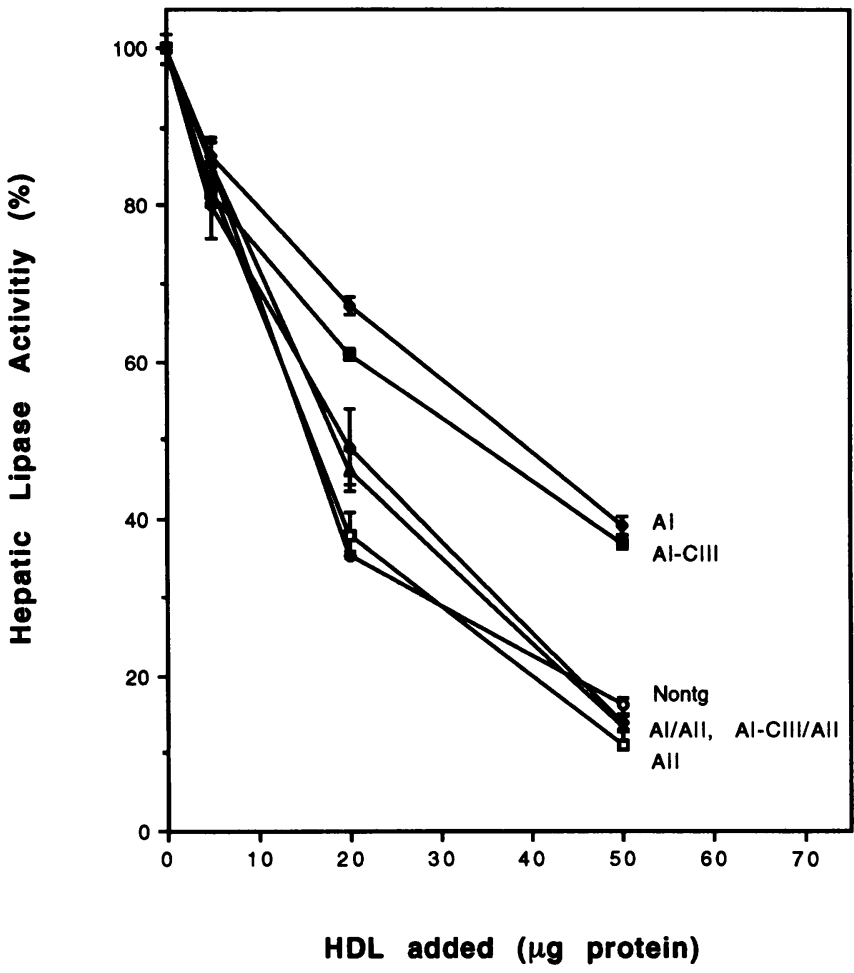

Figure 6. Inhibition of hepatic lipase activity by HDL prepared from mice of different genotypes. Pooled postheparin plasma (10 $\mu \mathrm{l})$ from nontransgenic mice was incubated with a gum arabic-stabilized emulsion using conditions selective for hepatic lipase activity in the presence of the indicated amounts of HDL isolated from mice of different genotype. Hydrolysis of radiolabeled triolein during a 1-h incubation was assessed (see Methods). When no HDL was added, the activity was $100 \%(12.8 \mu \mathrm{mol} \mathrm{FFA} / \mathrm{h})$.

indicate that apoA-II inhibits the remodeling of HDL particles by hepatic lipase subsequent to CE-TG interchange. To determine if HDL particles containing apoA-II might inhibit hepatic lipase, HDL were isolated from pooled plasma of transgenic mice and added to an in vitro hepatic lipase assay. This assay used a lipid emulsion and hepatic lipase activity obtained from postheparin plasma of nontransgenic mice. As in earlier studies (26), isolated HDL was found to inhibit hepatic lipase activity (Fig. 6). However, HDL prepared from mice expressing an apoA-I transgene without concomitant apoA-II transgene expression (i.e., A-I or AI-CIII) was less inhibitory than HDL from mice containing an apoA-II transgene or HDL from nontransgenic mice. With $50 \mu \mathrm{g}$ total HDL protein added, the order of inhibition was AII $>$ AI/AII, AI-CIII/AII $>$ nontg $>$ AICIII, AI. Bearing in mind that the nontransgenic HDL contains significant amounts of murine apoA-II, the order of inhibition follows the apoA-II/apoA-I ratio of HDL. The total hepatic lipase activity in postheparin plasma was not significantly different in magnitude in mice of different genotypes (nontg, $n$ $=3,12.8 \pm 0.6 \mu \mathrm{mol} \mathrm{FFA} / \mathrm{ml}$ per $\mathrm{h}$; AI-CIII $/$ CETP, $n=4$, $20.8 \pm 2.0 ; \mathrm{AI}-\mathrm{CIII} / \mathrm{AII} / \mathrm{CETP}, n=4,15.9 \pm 1.8$ ), indicating that the accumulation of HDL triglyceride is due to a difference in substrate rather than in the total amount of enzyme available.

In further studies we compared the activity of hepatic lipase on HDL in plasma of different transgenic mice. In the mouse hepatic lipase activity is found associated with $\operatorname{HDL}(14,42)$, so the activity of hepatic lipase on HDL can be assessed by 

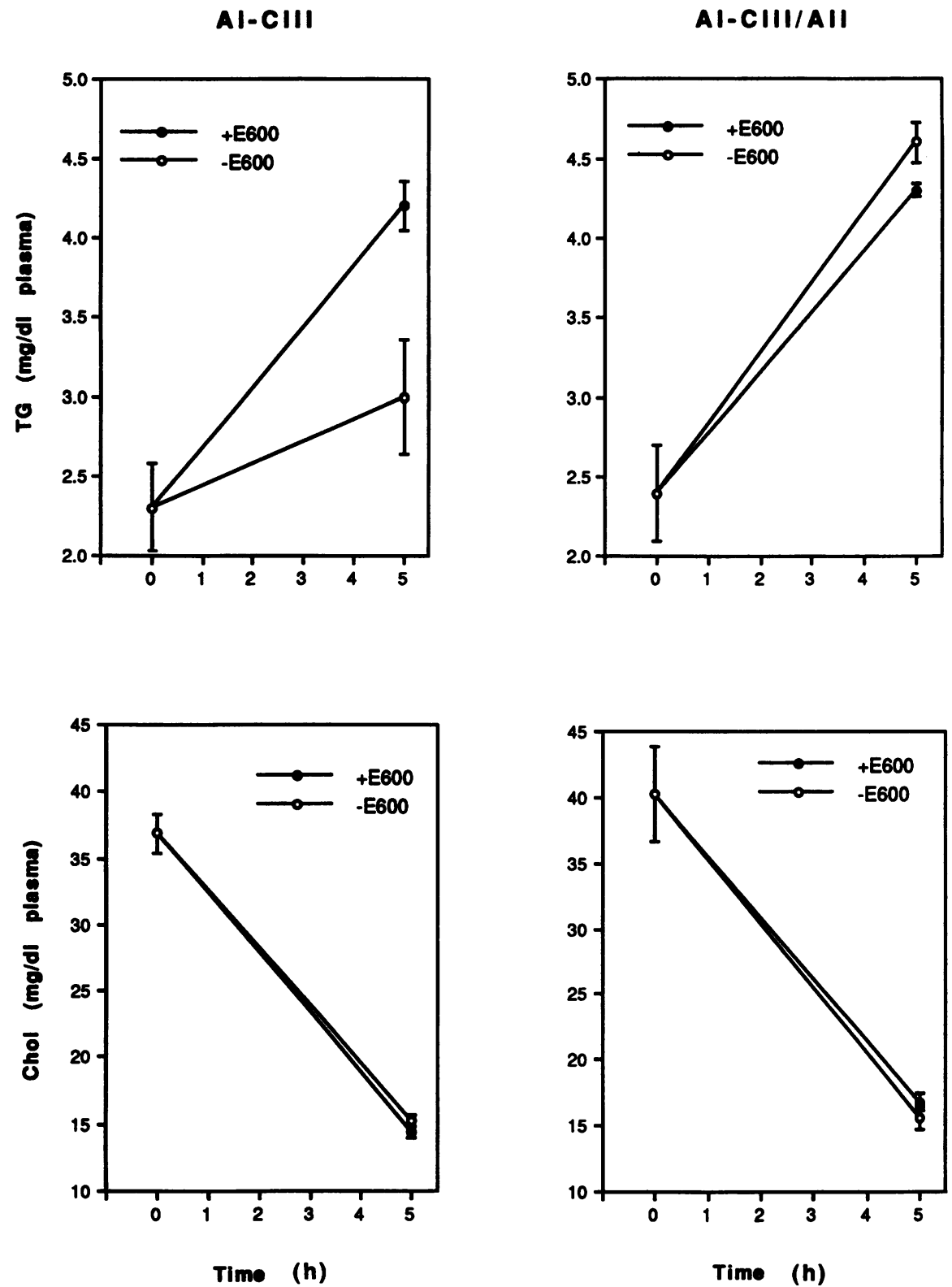

Figure 7. Plasma HDL cholesterol and triglyceride contents after incubation with rCETP and diethyl $p$-nitrophenylphosphate (E600). Freshly obtained and pooled plasma $(200 \mu \mathrm{l})$ was incubated with rCETP $(20 \mu \mathrm{g} /$ $\mathrm{ml}$ plasma $)$ and $\mathrm{E} 600(500 \mu \mathrm{M})$ for $5 \mathrm{~h}$. HDL was isolated by ultracentrifugation between densities 1.055 and $1.21 \mathrm{~g} / \mathrm{ml}$ (see Methods). Cholesterol and triglyceride were analyzed using enzymatic kits (Wako Bio-

Time (h) products).

incubation of plasma. Since the HDL triglyceride is low in mice, CETP was added to hypertriglyceridemic mouse plasma then incubated to enrich the HDL triglyceride. In plasma of apoAI/CIII transgenic mice incubation in the presence of CETP and lipase inhibitor $(+\mathrm{E} 600)$ resulted in a doubling of HDL triglyceride (Fig. 7, $P<0.05$ ). When the lipase inhibitor was omitted ( $-\mathrm{E} 600$ ), the increase in HDL triglyceride was much less pronounced, indicating active lipolysis of HDL triglyceride during incubation (Fig. 7). In contrast, incubation of plasma from AII/AI-CIII transgenic mice resulted in an increase of HDL triglyceride that was identical with or without the lipase inhibitor, and comparable to that obtained in AI-CIII transgenic mice with lipase inhibitor. The reduction of HDL cholesterol during the incubation was not affected by the presence of human apoA-II (Fig. 7). These results indicate that human apoA-II inhibits the lipolysis of HDL triglyceride as effectively as E600. Similar results were obtained without addition of CETP when plasma from AI-CIII/CETP mice was compared with AII/ AI-CIII/CETP mice (not shown).

\section{Discussion}

In this study we have explored the interaction of several genes influencing HDL metabolism by cross-breeding established lines of transgenic mice expressing various apolipoproteins and CETP. The focus was on the effects of apoA-II on CETP expression, based on an initial hypothesis that apoA-II might inhibit the lipid transfer activity of CETP. Although apoA-II did not prevent the reduction in HDL cholesterol mediated by CETP, the coexpression of apoA-II and CETP enhanced the accumulation of triglyceride in HDL, particularly in mice that were hypertriglyceridemic as a result of concomitant apoC-III overexpression. The triglyceride enrichment occurred specifically in particles containing human apoA-II. These results can be understood in the light of earlier studies which show that hepatic lipase acts preferentially on HDL triglycerides in rodents and humans, (for example, large triglyceride-rich HDL accumulate in human genetic hepatic lipase deficiency [43]), and other studies which show that hepatic lipase activity may be inhibited 
by apoA-II $(25,26)$. In the present study, HDL containing human apoA-II was found to inhibit hepatic lipase in an emulsion based assay and to resist the endogenous hepatic lipase activity in mouse plasma. Thus, apoA-II inhibits the hydrolysis of HDL triglyceride by hepatic lipase following CETP-mediated cholesteryl ester-triglyceride interchange. Hepatic lipase inhibition could also explain the resistance of HDL from hypertriglyceridemic mice expressing apoA-II to CETP-mediated changes in particle size and apoA-I, and phospholipid content, since hepatic lipase has phospholipase as well as triglyceride hydrolase activities and can mediate reduction in size and apoA-I content of core lipid-exchanged HDL particles $(44,45)$.

The lipid transfer activity of CETP appeared to be fully expressed in the presence of apoA-II, as seen both in reductions in HDL cholesteryl esters and increases in VLDL cholesteryl esters (Fig. 1; Table II). Although the comparison of HDL cholesterol values with and without CETP is complicated by the fact that mice of different genotypes started with different levels of HDL cholesterol, CETP produced marked reductions in HDL cholesterol both in absolute terms and as a percentage of baseline values (i.e., without CETP) in mice expressing apoA-II alone, apoA-I/apoA-II, and apoA-I/apoA-II/apoC-III. Similarly, CETP-mediated triglyceride transfer from VLDL into different mouse HDLs was not significantly influenced by the presence of apoA-II. Our findings failed to confirm the predictions of a recent in vitro study, where enrichment of $\mathrm{HDL}_{3}$ with apoA-II, or a comparison of LpA-I and LpA-I/A-II suggested inhibition of CETP lipid transfer activity by apoA-II (23). However, these inhibitory effects were only observed at extremely high ratios of HDL to acceptor (LDL), beyond the physiological range (23).

The finding that coexpression of apoA-II and CETP led to a significant increase in HDL triglyceride was unexpected. This effect was initially discovered when it was noted that in the presence of apoA-II, CETP produced a considerable decrease in HDL cholesterol without much change in HDL particle size. This suggested that the change in total neutral lipid content of HDL (i.e., triglyceride plus cholesteryl ester) might be limited in the presence of apoA-II. An increase in HDL triglycerides was subsequently documented, but only after precautions were taken to block lipolysis of HDL during lipoprotein separation by addition of the lipase inhibitor E600 to fresh plasma. This precaution might be necessary for potential observations of triglyceride enrichment of LpA-I/A-II in other settings. The failure to observe mild hypertriglyceridemia in human apoA-II transgenic mice in earlier studies might have been due to the lack of addition of a lipase inhibitor during sample processing (18). Comparing mice with and without CETP, the increase in HDL triglyceride was more pronounced when the apoA-II transgene was part of the genotype. Although the absolute increase in TG content was fairly subtle, TG became a more prominent component of HDL lipids in the presence of apoAII and CETP, as reflected in a reduction of CE/TG ratio from 22 in nontg mice to 1.6 in AI-CIII/A-II/CETP mice. Moreover, this effect of the apoA-II-CETP gene interaction was universal, i.e., it was observed in mice expressing apoA-II alone, apoAI/apoA-II, or apoA-I/apoA-II/apoC-III, and in mice of mixed genetic background as well as in mice bred towards the C57BL6 background (Tables III and II). Further confirming the specificity of this interaction, the effect of apoA-II on CETP was found to be confined to particles containing apoA-II as shown by immunoaffinity separation of LpA-I and LpA-I/A-II: only the latter particles became triglyceride enriched in the presence of CETP (Table IV).

The enrichment of HDL triglyceride in mice expressing both apoA-II and CETP transgenes suggests that apoA-II may be a physiological inhibitor of the action of hepatic lipase on HDL, consistent with the results of some earlier in vitro studies (25, 26), but in contrast to those of Mowri et al. (46). Thuren et al. (25) have performed elegant surface monolayer studies showing that at surface pressures likely relevant to an HDL particle, apoE stimulates hepatic lipase activity while apoA-II inhibits both the penetration of hepatic lipase into a phospholipid monolayer and also the phospholipase and triglyceride hydrolase activity of hepatic lipase within the monolayer. Jahn et al. (27) found that isolated apoA-II could act either as a stimulator or inhibitor of hepatic lipase depending on assay conditions: these authors suggested that apoA-II might be a physiological activator of hepatic lipase. In another study, Mowri et al. (46) suggested that apoA-II might stimulate the hydrolysis of HDL triglyceride.

In the present investigation, HDL isolated from mice of different genotypes inhibited the action of hepatic lipase in a lipid emulsion-based assay, and HDL containing human apoAII was resistant to hepatic lipase activity in incubated plasma. In the emulsion assay, the rank order of inhibition of the different HDLs varied according to their apoA-II/apoA-I ratio, and HDL isolated from mice overexpressing apoA-I without apoAII was much less inhibitory than the other HDLs (Fig. 6). Thus, our in vitro results add to the weight of evidence that apoA-II in HDL is inhibitory to hepatic lipase. Although the relevance of various in vitro assays of hepatic lipase activity to the effects of hepatic lipase on HDL can be questioned, the enrichment of HDL triglycerides in mice expressing apoA-II and CETP strongly suggests that apoA-II acts as an inhibitor of hepatic lipase in vivo. The fact that total plasma postheparin hepatic lipase activity was similar in mice of different genotypes, and that triglyceride enrichment of HDL particles was confined to the LpA-I/A-II fraction suggests that the inhibitory effects of apoA-II on lipase activity are exerted by rendering the HDL substrate unfavorable for hepatic lipase activity, most likely by the mechanisms suggested by Thuren et al. (25).

The synergistic interaction of CETP, apoC-III, and apoA-I to produce profound reductions in HDL size and apoA-I content was similar to that observed previously (16). Little CETPmediated reduction in HDL size, apoA-I, or total protein content was observed in apoCIII-AI mice in the presence of apoA-II, even though the percent reduction of HDL cholesterol was only slightly less than that observed in the absence of apoA-II. It is notable that the apoA-II content of plasma and HDL was not reduced as a result of CETP expression in mice of any genotype (Table I; Fig. 3). These findings can be understood in the light of our hypothesis that apoA-II inhibits the action of hepatic lipase on HDL, since lipase action on triglyceride-enriched HDL is known to result in reductions of HDL size and apoA-I content, both in vitro and in vivo $(45,47)$. Apart from hepatic lipase inhibition, apoA-II may also render HDL particles resistant to CETP-mediated size changes by increasing the structural stability of HDL particles, as suggested from in vitro studies where apoA-II inhibited the size reduction of phospholipid/cholesterol/apoA-I particles mediated by CETP (22). The dimeric structure of human apoA-II may contribute to the resistance to remodeling of HDL by CETP (48).

The increase in VLDL cholesteryl esters due to CETP ex- 
pression was more obvious in the presence of human apoA-II (Fig. 1). At the lower levels of plasma CETP $(2-3 \mu \mathrm{g} / \mathrm{ml})$ used in the present study, the increase in VLDL cholesteryl ester was very small in mice expressing CETP alone (Fig. 1 and [28]). In mice expressing CETP without other transgenes an increase in VLDL cholesteryl esters only becomes prominent at very high levels of CETP expression when downregulation of hepatic LDL receptors also occurs (49). Even with humanlike CETP levels, there was a prominent increase in VLDL cholesteryl esters in mice expressing apoA-II/CETP, apoA-I/ apoC-III/CETP, and apoA-I/apoC-III/apoA-II/CETP (Fig. 1). Mice of these genotypes were also hypertriglyceridemic, compared with nontransgenic littermates (Table I). The hypertriglyceridemia probably results from reduced clearance of VLDL particles due to displacement of VLDL apoE by apoCIII in apoC-III transgenic mice and possibly from a similar mechanism in apoA-II transgenic mice (21). Thus, the CETPmediated increase in VLDL cholesteryl esters may only become prominent in mice with delayed clearance of VLDL particles, resulting either from downregulation of LDL receptors due to very high levels of CETP expression (49), or from overexpression of various apolipoproteins leading to delayed VLDL clearance (12). Aside from hydrolysis of HDL lipids, hepatic lipase has been postulated to act on small VLDL and remnant lipoproteins (50). In addition by acting as a bridge between circulating lipoproteins and liver cell surface proteoglycans, hepatic lipase might anchor these particles to cells and facilitate their catabolism (51). If apoA-II also inhibits hepatic lipase mediated metabolism of remnants, this mechanism could also contribute to the cholesterol enrichment of VLDL seen when the apoA-II and CETP transgenes are present.

One potential reservation concerning our conclusions is that most of the studies were done in genetically heterogenous mice. However, the increase in HDL triglyceride resulting from human CETP-apoA-I interaction was documented in mice predominantly in the C57BL6 background, and the composition and size data were generated from pooled plasma from multiple animals, minimizing effects of uncontrolled variables (genetic or otherwise). Moreover, the compositional and size data were used to generate a hypothesis, i.e., that apoA-II inhibits hepatic lipase activity, which was subsequently tested in vitro where effects of genetic variability are likely to be small.

The present findings suggest that one function of apoA-II may be to limit the remodeling of HDL by hepatic lipase, helping to preserve a minimum level of HDL particles bearing apoAI and apoA-II. There is a well-known inverse relationship between plasma triglyceride and HDL cholesterol levels, due to the CETP-mediated exchange of HDL cholesteryl esters with VLDL triglycerides. However, the effects of hypertriglyceridemia on apoA-I levels are not as pronounced as the effects on HDL cholesterol (52), probably because of relatively stable levels of LpA-I/A-II. Plasma apoA-I levels are more variable than apoA-II levels in human populations, reflecting marked variation in LpA-I levels (e.g., due to gender [53]), compared with LpA-I/A-II levels. The resistance of apoA-II-enriched particles to remodeling by CETP documented herein provides a mechanistic explanation for the consistency of LpA-I/A-II levels in human populations.

Do the properties of apoA-II revealed in the present study have any bearing on its putative proatherogenic properties? Although speculative, our findings suggest three mechanisms. First, in animals containing CETP, apoA-II enhances accumula- tion of CE in triglyceride-rich lipoproteins, resulting in an overall defect in the normal CETP-mediated decrease of plasma cholesterol (Table I; Fig. 1). Second, apoA-II appears to be a physiological inhibitor of hepatic lipase and there is evidence that hepatic lipase promotes reverse cholesterol transport by promoting the movement of cholesterol and CE from HDL into hepatocytes (54). Third, the apoA-II limits the formation of small HDL particles. Small HDL particles formed in the presence of hypertriglyceridemia may be optimal mediators of cholesterol removal from cells (55). Human hepatic lipase transgenic mice have reduced HDL cholesterol and decreased aortic cholesterol content on an atherogenic diet, emphasizing the role of hepatic lipase in reverse cholesterol transport (56). Thus apoA-II may interfere with reverse cholesterol transport normally mediated by apoA-I and CETP.

\section{Acknowledgments}

This work was supported by grants HL-21006, HL-45095, HL-33714, and HL-32435 from the National Institutes of Health.

\section{References}

1. Miller, G. J., and N. E. Miller. 1975. Plasma high density lipoprotein concentration and development of ischaemic heart disease. Lancet. 1:16-19.

2. Gordon, T., W. P. Castelli, M. C. Hjortland, W. B. Kannel, and T. R. Dawber. 1977. High density lipoprotein as a protective factor against coronary heart disease: the Framingham study. Am. J. Med. 62:701-714.

3. Tall, A. R. 1990. Plasma high density lipoproteins. Metabolism and relationship to atherogenesis. J. Clin. Invest. 86:379-384.

4. Eisenberg, S. 1984. High density lipoprotein metabolism. J. Lipid Res. 25:1017-1058.

5. Tall, A. R. 1993. Plasma cholesteryl ester transfer protein. J. Lipid Res. 34:1255-1274.

6. Patsch, J. R., S. Prasad, A. M. Gotto, and G. Bengtson-Olivecrona. 1984. Postprandial lipemia. A key for the conversion of high density lipoprotein 2 into lipoprotein 3 by hepatic lipase. J. Clin. Invest. 74:2017-2023.

7. Brown, M. L., A. Inazu, C. B. Hesler, L. B. Agellon, C. Mann, M. E. Whitlock, Y. L. Marcel, R. W. Milne, J. Koizumi, H. Mabuchi, et al. 1989. Molecular basis of lipid transfer protein deficiency in a family with increased high-density lipoproteins. Nature (Lond.). 342:448-451.

8. Takahashi, K., X-C. Jiang, N. Sakai, S. Yamashita, K. Hirano, H. Bujo, H. Yamazaki, J. Kusonoki, T. Miura, P. Kussie, et al. 1993. A missense mutation in the cholesteryl ester transfer protein gene with possible dominant effects on plasma high density lipoproteins. J. Clin. Invest. 92:2060-2064.

9. Breslow, J. L. 1993. Transgenic mouse models of lipoprotein metabolism and atherosclerosis. Proc. Natl. Acad. Sci. USA. 90:8314-8318.

10. Rubin, E. M., B. Y. Ishida, S. M. Clift, and R. M. Krauss. 1991. Expression of human apolipoprotein A-I in transgenic mice results in reduced plasma levels of murine apolipoprotein A-I and the appearance of two new high density lipoprotein size subclasses. Proc. Natl. Acad. Sci. USA. 88:434-438.

11. Rubin, E. M., R. M. Krauss, E. R. Spangler, J. G. Verstuyft, and S. M. Clift. 1991. Inhibition of early atherogenesis in transgenic mice by human apolipoprotein AI. Nature (Lond.). 353:265-267.

12. Ito, Y., N. Azrolan, A. O'Connell, A. Walsh, and J. L. Breslow. 1990. Hypertriglyceridemia as a result of human apo CIII gene expression in transgenic mice. Science (Wash. DC). 249:790-793.

13. Marotti, K. R., C. K. Castle, R. W. Murray, E. F. Rehberg, and G. W. Melchior. 1992. The role of cholesterol ester transfer protein in primate apolipoprotein A-I metabolism. Insights from transgenic mice. Arterioscler. Thromb. 12:736-744.

14. Melchior, G. W., C. K. Castle, R. W. Murray, W. L. Blake, D. M. Dinh, and K. R. Marriotti. 1994. Apolipoprotein A-I metabolism in cholesteryl ester transfer protein transgenic mice. J. Biol. Chem. 269:8044-8051.

15. Hayek, T., T. Chajek-Shaul, A. Walsh, L. B. Agellon, P. Moulin, A. R. Tall, and J. L. Breslow. 1992. An interaction between the human cholesterol ester transfer protein (CETP) and apolipoprotein A-I genes in transgenic mice results in a profound CETP-mediated depression of high density lipoprotein cholesterol levels. J. Clin. Invest. 90:505-510.

16. Hayek, T., N. Azrolan, R. Verdery, A. Walsh, T. Chajek-Shaul, L. Agellon, A. R. Tall, and J. L. Breslow. 1993. Hypertriglyceridemia and cholesterol ester transfer protein (CETP) expression interact to dramatically alter HDL levels, 
particle size and metabolism: studies in transgenic mice. J. Clin. Invest. 92:11431152.

17. Marotti, K. R., C. K. Castle, T. P. Boyle, A. H. Lin, R. W. Murray, and G. W. Melchior. 1993. Severe atherosclerosis in transgenic mice expressing simian cholesteryl ester transfer protein. Nature (Lond.). 364:73-75.

18. Schultz, J. R., E. L. Gong, M. R. McCall, A. V. Nichols, S. M. Clift, and E. M. Rubin. 1992. Expression of human apolipoprotein A-II and its effect on high density lipoproteins in transgenic mice. J. Biol. Chem. 267:21630-21636.

19. Schultz, J. R., J. G. Verstuyft, E. L. Gong, A. V. Nichols, and E. M. Rubin. 1993. Protein composition determines the anti-atherogenic properties of HDL in transgenic mice. Nature (Lond.). 365:762-764.

20. Warden, C. H., C. C. Hedrick, J-H. Qiao, L. W. Castellani, and A. J. Lusis. 1993. Atherosclerosis in transgenic mice overexpressing apolipoprotein A-II. Science (Wash. DC). 261:469-472.

21. Hedrick, C. C., L. W. Castellani, C. H. Warden, D. L. Puppione, and A. J. Lusis. 1993. Influence of mouse apolipoprotein A-II on plasma lipoproteins in transgenic mice. J. Biol. Chem. 268:20676-20682.

22. Rye, K. A., K. H. Garrety, and P. J. Barter. 1992. Change in the size of reconstituted high density lipoproteins during incubation with cholesteryl ester transfer protein: the role of apolipoproteins. J. Lipid Res. 33:215-224.

23. Lagrost, L., L. Persegol, C. Lallemant, and P. Gambert. 1994. Influence of apolipoprotein particles on cholesteryl ester transfer protein activity. Particles containing various proportions of apolipoprotein AI and AII. J. Biol. Chem. 269:3189-3197.

24. Ikewaki, K., D. J. Rader, T. Sakamoto, M. Nishwaki, J. R. Schaefer, T. Ishikawa, T. Fairwell, L. A. Zech, H. Nakamura, M. Nagano, and H. B. Brewer. 1993. Delayed catabolism of high density lipoprotein apolipoprotein A-I and AII in human cholesteryl ester transfer protein deficiency. J. Clin. Invest. 92:16501658.

25. Thuren, T., R. W. Wilcox, P. Sisson, and P. Waite. 1991. Hepatic lipase hydrolysis of lipid. Regulation by apolipoproteins. J. Biol. Chem. 266:48534861 .

26. Kubo, M., Y. Matsuzawa, S. Yokoyama, S. Tajima, K. Ishikawa, A. Yamamoto, and S. Tarui. 1982. Mechanism of inhibition of hepatic triglyceride lipase from human postheparin plasma by apolipoproteins AI and AII. J. Biochem. 92:865-870.

27. Jahn, C. E., J. C. Osborne, E. J. Schaffer, and H. B. Brewer. 1983. Activation of the enzyme activity of hepatic lipase by apolipoprotein A-II. Characterization of a major component of high density lipoprotein as the activating plasma component in vitro. Eur. J. Biochem. 131:25-29.

28. Agellon, L. B., A. Walsh, T. Hayek, P. Moulin, X-C. Jiang, S. A. Shelanski, J. L. Breslow, and A. R. Tall. 1991. Reduced high density lipoprotein cholesterol in human cholesterol ester transfer protein transgenic mice. J. Biol. Chem. 266:10796-10801.

29. Jiang, X-C., L. B. Agellon, A. Walsh, J. L. Breslow, and A. R. Tall. 1992. Dietary cholesterol increases transcription of the human cholesteryl ester transfer protein gene in transgenic mice. Dependence on natural flanking sequences. $J$. Clin. Invest. 90:1290-1295.

30. Marcel, Y. L., R. McPherson, M. Hogue, H. Czarnecka, Z. Zawadski, P. K. Weech, M. E. Whitlock, A. R. Tall, and R. W. Milne. 1990. Distribution and concentration of cholesterol ester transfer protein in plasma of normolipemic subjects. J. Clin. Invest. 85:10-17.

31. Tall, A. R., E. Granot, R. Brocia, I. Tabas, C. Hesler, K. Williams, and M. Denke. 1987. Accelerated transfer of cholesteryl esters in dyslipidemic plasma. J. Clin. Invest. 79:1217-1225.

32. Jiao, S., T. G. Cole, R. T. Kitchens, B. Pfleger, and G. Schonfeld. 1990. Genetic heterogeneity of lipoproteins in inbred strains of mice: analysis by gel permission chromatography. Metab. Clin. Exp. 39:155-160.

33. Allain, C. A., L. S. Poon, C. S. G. Chan, W. Richmond, and P. C. Fu. 1974. Enzymatic determination of total serum cholesterol. Clin. Chem. 20:470475.

34. Richmond, W. 1976. Use of cholesterol oxidase for assay of total and free cholesterol in serum by continuous flow analysis. Clin. Chem. 22:1579-1588.

35. Buloco, G., and H. David. 1973. Quantitative determination of serum triglycerides by the use of enzymes. Clin. Chem. 19:476-482.

36. Tamayama, M., S. Itoh, T. Nagasaki, and I. Tanimizu. 1977. A new enzymatic method for determination of serine choline-containing phospholipids. Clin. Chim. Acta. 79:93-98.

37. Markwell, M. A., S. M. Haas, N. E. Tolbert, and L. L. Bieber. 1981 Protein determination in membrane and lipoprotein samples: manual and automated procedures. Methods Enzymol. 72:296-303.

38. Blanche, P. J., E. L. Gong, T. M. Forte, and A. V. Nichols. 1981. Characterization of human high density lipoproteins by gradient gel electrophoresis. Biochim. Biophys. Acta. 665:408-418.

39. Nichols, A. V., R. M. Krauss, and T. A. Musliner. 1986. Nondenaturing polyacrylamide gradient gel electrophoresis. Methods Enzymol. 128:417-431.

40. Baginsky, M. L., and M. V. Brown. 1979. A new method for the measurement of lipoprotein lipase in postheparin plasma using sodium dodecyl sulfate for the inactivation of hepatic triglyceride lipase. J. Lipid Res. 20:548-556.

41. Belfrage, P., and M. Vaughan. 1969. Simple liquid-liquid partition system for isolation of labeled oleic acid from mixtures with glycerides. J. Lipid Res. 10:341-344.

42. Peterson, J., G. Bengtsson-Olivecrona, and T. Olivecrona. 1986. Mouse preheparin plasma contains high levels of hepatic lipase with low affinity for heparin. Biochim. Biophys. Acta. 878:65-70.

43. Hegele, R. A., J. A. Little, C. Vezina, G. F. Maguire, L. Tu, T. S. Wolever, D. J. Jenkins, and P. W. Connelly. 1993. Hepatic lipase deficiency. Clinical, biochemical, and molecular genetic characteristics. Arterioscler. Thromb. 13:720728.

44. Deckelbaum, R. J., R. Ramakrishnan, S. Eisenberg, T. Olivecrona, and G. Bengtson-Olivecrona. 1992. Triglycerol and phospholipid hydrolysis in human plasma lipoproteins: role of lipoprotein and hepatic lipase. Biochemistry. 31:85448551.

45. Clay, M. A., H. H. Newnham, and P. J. Barter. 1991. Hepatic lipase promotes a loss of apolipoprotein A-I from triglyceride-enriched human high density lipoproteins during incubation in vitro. Arterioscler. Thromb. 11:415422.

46. Mowri, H-O., W. Patsch, L. D. Smith, A. M. Gotto, and J. R. Patsch 1992. Different reactivities of high density lipoprotein 2 subfractions with hepatic lipase. J. Lipid Res. 33:1296-1279.

47. Rader, D. J., G. Castero, L. A. Zech, J-C. Fruchart, and H. B. Brewer 1991. In vivo metabolism of apolipoprotein A-I on high density lipoprotein particles LpA-I and LpA-II. J. Lipid Res. 32:1849-1859.

48. Calabresi, I., C. Banfi, C. R. Sirtori, and G. Franceschini. 1992. Apolipoprotein A-II modulates HDL remodeling in plasma. Biochim. Biophys. Acta. 1124:195-198.

49. Jiang, X-C., L. Masucci-Magoulas, J. Mar, M. Lin, A. Walsh, J. L. Breslow, and A. R. Tall. 1993. Down-regulation of mRNA for the low density lipoprotein receptor in transgenic mice containing the gene for human cholesteryl ester transfer protein. Mechanism to explain accumulation of lipoprotein B particles. J. Biol. Chem. 268:27406-27412.

50. Goldberg, I. J., W. S. Blaner, T. M. Vanni, M. Moukides, and R. Ramakrishnan. 1990. Role of lipoprotein lipase in the regulation of high density lipoprotein apolipoprotein metabolism. Studies in normal and lipoprotein lipase-inhibited monkeys. J. Clin. Invest. 86:463-473.

51. Ji, Z-S., S. Fazio, Y-L. Lee, and R. W. Mahley. 1994. Secretion-capture role for apolipoprotein $\mathrm{E}$ in remnant lipoprotein metabolism involving cell surface heparin sulfate proteoglycans. J. Biol. Chem. 269:2764-2772.

52. Phillips, N. R., R. J. Havel, and J. P. Kane. 19??. Serum apolipoprotein A-I levels:relationship to lipoprotein lipid levels and selected demographic variables. Am. J. Epidemiol. 116:302-313.

53. Moulin, P., M. C. Cheung, C. Bruce, S. Zhong, T. Cocke, H. Richardson, and A. R. Tall. 1994. Gender effects on the distribution of the cholesteryl ester transfer protein in apolipoprotein A-I lipoprotein subpopulations. J. Lipid Res. In press.

54. Bamberger, M., S. Lund-Katz, M. C. Phillips, and G. H. Rothblat. 1985. Mechanism of the hepatic lipase induced accumulation of high-density lipoprotein cholesterol by cells in culture. Biochemistry. 24:3693-3701.

55. Castro, G. R., and C. J. Fielding. 1988. Early incorporation of cell-derived cholesterol into pre- $\beta$-migrating high-density lipoprotein. Biochemistry. 27:2529.

56. Busch, S. J., R. L. Barnhart, G. A. Martin, M. C. Fitzgerald, M. T. Yates, S. J. T. Mao, C. E. Thomas, and R. L. Jackson. 1994. Human hepatic triglyceride lipase expression reduces high density lipoprotein and aortic cholesterol in cholesterol-fed transgenic mice. J. Biol. Chem. 269:16376-16382. 